\title{
Editorial
}

\section{Making nutrition work for development}

Despite significant progress in the fight against malnutrition, large populations in low- and middle-income countries are suffering from hunger and micronutrient deficiencies $^{(1)}$. In various African countries and populations of low socio-economic strata worldwide, additional and better-targeted efforts are needed to break the vicious cycle of malnutrition. Against this backdrop, diet-related chronic diseases are expanding rapidly and require urgent attention $^{(2)}$. In addition, emerging environmental threats such as climate change, population growth, changing social structures and deterioration of natural resources and livelihoods will require new ways of thinking to mitigate the impact on nutritional status.

Fortunately, as explained in an accompanying editorial by Anna Lartey - incoming President for the International Union of Nutritional Sciences (IUNS) - in the current issue, there presently is a considerable amount of attention on nutrition in low- and middle-income countries. To mention just a few, the launch of the Scaling Up Nutrition movement, the organization of the UN HighLevel Meeting on Non-communicable Diseases and the G8 meetings during the past years are important events that have placed nutrition at the centre stage of international development.

As this month's issue of Public Health Nutrition illustrates, there is no lack of nutrition research from low- and middle-income countries. Research findings from several regions of the world are included; i.e. Africa: Senegal ${ }^{(3)}$,

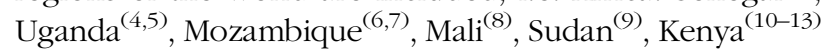
and South Sudan ${ }^{(14)}$; Asia: Philippines, Malaysia and Indonesia $^{(15)}$ India $^{(16-18)}$, Pakistan ${ }^{(19)}$ and Sri Lanka ${ }^{(20)}$; the Caribbean: Trinidad and Tobago ${ }^{(21)}$; and Latin America: Colombia $^{(22)}$. This research reflects the wide range of nutritional issues that low- and middle-income countries face, i.e. the prevention and management of diet- and lifestyle-related non-communicable diseases ${ }^{(15,17,20,21)}$, nutritional deficiencies ${ }^{(4,5,7-11,13,16,19)}$ or a combination of both $^{(21)}$. Other papers focus on food security ${ }^{(14)}$, programme evaluation $^{(12,18)}$ or on methodological issues such as the assessment of anthropometry ${ }^{(3)}$ or dietary intake ${ }^{(6)}$.

Importantly, in the vast majority of these papers, the leading author is associated with an institution based in low- and middle-income countries. Home-grown research is essential to address nutrition in low- and middle-income countries as it generates contextual knowledge for policy makers to take action. It is essential to help policy makers make an informed decision for political action. It is important that this process is rationalized to save valuable resources, particularly in low- and middle-income countries where funding and capacity are stretched ${ }^{(23)}$. Recent initiatives from the SUNRAY project ${ }^{(24)}$ and The Sackler Institute for Nutrition Science ${ }^{(25)}$ are a significant start to guide nutrition research in low- and middle-income countries. However, they will require further appropriation in the research community, in particular those working in low- and middle-income countries. An important way to get the priorities right will be to link nutrition researchers with their policy makers and other stakeholders to define a research agenda.

The time is ripe to reflect on the role of nutrition research in international development and policies. Public Health Nutrition will continue to publish papers about nutrition in low- and middle-income countries, and from researchers in those countries, and we will continue to serve as a forum for developing ideas to link nutrition research to programmes and policies. Beyond the role that our and other journals can play, we note that for the first time since its creation in 1946, the IUNS will be led by an African scientist. This is important, as the IUNS is the highest body to advocate for nutrition research globally. The upcoming joint $\mathrm{FAO} / \mathrm{WHO}$ Second International Conference on Nutrition and the 2013 IUNS congress in Granada will mobilize a large body of nutrition researchers from low- and middle-income countries. These are unprecedented opportunities for the nutrition community. Critical issues such as the translation of nutrition research into effective action and the development and propagation of sustainable dietary patterns cannot be ignored. RSVP, anybody?

Carl Lachat First Editor Email: carl.lachat@ugent.be

Department of Food Safety and Food Quality Ghent University, Ghent, Belgium

Unit of Nutrition and Child Health Institute for Tropical Medicine, Antwerp, Belgium

\section{References}

1. Stevens GA, Finucane MM, Paciorek CJ et al. (2012) Trends in mild, moderate, and severe stunting and underweight, and progress towards MDG 1 in 141 developing countries: a systematic analysis of population representative data. Lancet 380, 824-834. 
2. Lim SS, Vos T, Flaxman AD et al. (2012) A comparative risk assessment of burden of disease and injury attributable to 67 risk factors and risk factor clusters in 21 regions, 1990-2010: a systematic analysis for the Global Burden of Disease Study 2010. Lancet 380, 2224-2260.

3. Garenne M, Maire B, Fontaine O et al. (2013) Adequacy of child anthropometric indicators for measuring nutritional stress at population level: a study from Niakhar, Senegal. Public Health Nutr 16, 1533-1539.

4. Baingana R, Matovu-Kasozi D \& Garrett D (2013) The importance of controlling for the acute-phase response in the population-based assessment of vitamin A status: a study in children of pre-school age in Uganda. Public Health Nutr 16, 1540-1547.

5. Muhangi L, Lule SA, Mpairwe H et al. (2013) Maternal HIV infection and other factors associated with growth outcomes of HIV-uninfected infants in Entebbe, Uganda. Public Health Nutr 16, 1548-1557.

6. Korkalo L, Erkkola M, Fidalgo L et al. (2013) Food photographs in portion size estimation among adolescent Mozambican girls. Public Health Nutr 16, 1558-1564.

7. Nhampossa T, Sigaúque B, Machevo S et al. (2013) Severe malnutrition among children under the age of 5 years admitted to a rural district hospital in southern Mozambique. Public Health Nutr 16, 1565-1574.

8. Gewa CA, Leslie TF \& Pawloski LR (2013) Geographic distribution and socio-economic determinants of women's nutritional status in Mali households. Public Health Nutr 16, 1575-1585.

9. Medani AMMH, Elnour AA \& Saeed AM (2013) Excessive iodine intake, water chemicals and endemic goitre in a Sudanese coastal area. Public Health Nutr 16, 1586-1592.

10. Neumann CG, Bwibo NO, Jiang L et al. (2013) School snacks decrease morbidity in Kenyan schoolchildren: a cluster randomized, controlled feeding intervention trial. Public Health Nutr 16, 1593-1604.

11. Macharia-Mutie CW, Omusundi AM, Mwai JM et al. (2013) Simulation of the effect of maize porridge fortified with grain amaranth or micronutrient powder containing NaFeEDTA on iron intake and status in Kenyan children. Public Health Nutr 16, 1605-1613.

12. Havemann K, Pridmore P, Tomkins A et al. (2013) What works and why? Evaluation of a community nutrition programme in Kenya. Public Health Nutr 16, 1614-1621.

13. Adongo AO, Shell-Duncan B \& Prisca TJ (2013) Effect of settlement on nutrition and health status of pastoral Gabra women of reproductive age in Kalacha Location, Marsabit County, Kenya. Public Health Nutr 16, 1622-1630.
14. Tappis H, Doocy S, Paul A et al. (2013) Food security and development in South Sudan: a call to action. Public Health Nutr 16, 1631-1636.

15. Lipoeto NI, Geok LK \& Angeles-Agdeppa I (2013) Food consumption patterns and nutrition transition in South-East Asia. Public Health Nutr 16, 1637-1643.

16. Deb D, Biswas A, Ghose A et al. (2013) Nutritional deficiency and arsenical manifestations: a perspective study in an arsenic-endemic region of West Bengal, India. Public Health Nutr 16, 1644-1655.

17. Veena SR, Krishnaveni GV, Karat SC et al. (2013) Testing the fetal overnutrition hypothesis; the relationship of maternal and paternal adiposity to adiposity, insulin resistance and cardiovascular risk factors in Indian children. Public Health Nutr 16, 1656-1666.

18. Aguayo VM, Paintal K \& Singh G (2013) The Adolescent Girls' Anaemia Control Programme: a decade of programming experience to break the inter-generational cycle of malnutrition in India. Public Health Nutr 16, $1667-1676$.

19. Rahman MA, Rahman B \& Ahmed N (2013) High blood manganese in iron-deficient children in Karachi. Public Health Nutr 16, 1677-1683.

20. Katulanda P, Jayawardana R, Ranasinghe $\mathrm{P}$ et al. (2013) Physical activity patterns and correlates among adults from a developing country: the Sri Lanka Diabetes and Cardiovascular Study. Public Health Nutr 16, 1684-1692.

21. Sheehy T \& Sharma S (2013) Trends in energy and nutrient supply in Trinidad and Tobago from 1961 to 2007 using FAO food balance sheets. Public Health Nutr 16, 1693-1702.

22. Garcia S, Sarmiento OL, Forde I et al. (2013) Socioeconomic inequalities in malnutrition among children and adolescents in Colombia: the role of individual-, household- and community-level characteristics. Public Health Nutr 16, 1703-1718.

23. Mckee M, Stuckler D \& Basu S (2012) Where there is no health research: what can be done to fill the global gaps in health research? PLoS Med 9, e1001209.

24. Anonymous (2013) SUNRAY Sustainable Nutrition Research for Africa in the Years to come. http://www.sunrayafrica. co.za

25. The Sackler Institute for Nutrition Science (2013) A Global Agenda for Nutrition Science. Outcome of a collaborative process between academic and non profit researchers and the World Health Organization. New York: The Sackler Institute for Nutrition Science. 